\title{
Simulation Model for Stochastic Analysis and Performance Evaluation of Condensate System of a Thermal Power Plant
}

\author{
Sorabh Gupta ${ }^{a^{*}}$ and P. C. Tewari ${ }^{\mathrm{b}}$ \\ ${ }^{a}$ Department of Mechanical Engineering, Haryana College of Technology and Management, Kaithal (Haryana), \\ and ${ }^{b}$ Mechanical Engineering, NIT, Kurukshetra (Haryana), India.
}

\begin{abstract}
This paper discusses the stochastic analysis and performance evaluation of condensate system of a thermal plant. These opportunities will be identified by evaluation of a simulation model to be built for the condensate system. The present system under study consists of six subsystems A, B, C, D, E, and F arranged in series with two feasible states: working and failed. After drawing transition diagram, differential equations are generated and then a probabilistic simulated simulation model using Markov approach has been developed considering some assumptions. Performance matrix for each subsystem is also developed, which provide various availability levels. On the basis of this study, performance of each subsystem of condensate system is evaluated and then maintenance decisions are made for subsystems.
\end{abstract}

Key words: Transition diagram, Markov approach, Performance matrix and Maintenance decisions.

\section{Introduction}

The importance of obtaining a highly reliable system has recently been recognized with increasing automation and use of highly complex systems. Lieberman (1973) states that a probabilistic analysis of the system under given operative conditions is helpful in the design modification, for minimum failure of the system and thus to optimise the system working. As mentioned by Goel and Shrivastava (1991), in repairable systems, the dependent structure for failure and repair times has been ignored by reliability researchers; the above-mentioned authors considered a correlated structure for the problem and obtained some reliability measures. Other papers in this area are Goel et al. (1994) and Goel et al. (1995). In this paper, two-unit systems with a repair facility as considered. Since the exact computation of the reliability for a large-scale and complex network generally requires exponential time, a variety of alternative methods to estimate the network reliability using Markov death-birth process have been proposed. A short list of them includes Mazumdar (1975), Kumamoto et al. (1977) and Fishman (1986).

Availability/performance measures for a two-unit system with repair facility were obtained by several authors under different assumptions. Some of the notable contributions in this area are Osaki (1980), Ravichandran (1981) and Pijnenburg et al. (1993). According to Rajamanickam et al.

\footnotetext{
* Corresponding author: E-mail: pctewari1@rediffmail.com
}

(1997), in most of the discussions, it is assumed that the failure times and repair times for the components are independently distributed. Corder (1976) describes that in a process plant the raw material is processed through various equipment to achieve the final product. The production suffers due to failure of any intermediate system even for a small interval of time. The cause of failure may be due to poor design, system complexity, poor maintenance, lack of communication and coordination, defective planning, lack of expertise/experience and scarcity of inventories. Thus, to run a process plant, highly skilled/experienced maintenance personnel are required. A thermal power plant is a complex engineering system comprising of various systems: Coal handling, Steam and water, Flue gas and air, Cooling Water, Crushing, Ash handling, Power Generation, Feed water and Condensate system connected either in series or in parallel or in the combination of both (Arora and Kumar (1993) and Arora et al. (1995)). To achieve the goal of maximum power generation, it is required to run the various subsystem of the concerned system of plant, failure free for a long duration. These subsystems are subjected to random failure and can be brought back into service after repairs/replacement. The failures of sub-systems and their components depend upon the operating conditions and repair policies used, and are difficult to predict precisely. Performance analysis provides a 
tool to economise on operational parameters in order to ensure the maximum possible level of system availability.

According to Raje et al. (2000), for the prediction of availability, several mathematical models, as described by Dhillon (1983) and Balaguruswamy (1984), which handle wide degree of complexities. Most of these models, for example Somani et al. (1992), Krishnamurthi et al. (1996) and Sahner (1996), are based on the Markovian approach, wherein the failure and the repair rates are assumed to be constant. In other words, the times to failure and the times to repair follow exponential distribution. Reliability analysis techniques have been gradually accepted as standard tools for the planning and operation of automatic and complex thermal power plants. Systems being built are increasingly complex and large; their components are exhibiting behaviors and interactions that are becoming more and more difficult to model and analyze using existing conventional tools. Markov Chains (MCs) and their extensions have proven to be a versatile tool for modeling complex dynamic component behavior. They have been extensively used for dependability analysis of dynamic systems and many tools have adopted, directly or indirectly, MCs as their formalism. During the past decade a lot of study, for example Butler (1986), Koren and Gaertner (1987) and Ciardo et al. (1989), has been done by on analysis tools for reliability, availability, performance and performability modeling.

Stanley and Malhoit (2001) concludes that the traditional Markov and Markov cut set approaches are able to produce exact answers when system components have exponential failure and repair rates. Ocon and Cazrola (2004) reveals that the maintenance of repairable systems has been widely studied by many authors, considering different focus of interest, such as the repair/replacement policy, periodic inspections, degrading, optimization problems, among other topics. Boudali and Dugan (2005), states that now a days, reliability analysis has become an integral part of system design. This is especially true for systems performing critical applications. The usage of such tools becomes therefore crucial. Systems being built are increasingly complex and large; their components are exhibiting behaviors and interactions that are becoming more and more difficult to model and analyze using existing conventional tools. Kiureghian et al. (2007) found that one is often interested in identifying critical components within a system, particularly in the context of upgrading the system availability or reliability, or reducing the duration of its downtimes. In a complex system with numerous components, identification of critical components is not straightforward.

In the present article, availability of a critical condensate system in the thermal plant has been worked out using a Markovian approach. The system model for the plant has been developed on the basis of an actual study conducted in a thermal plant located in North India. Assuming failure and repair rates as constant, the expression for steady state availability is derived. The effect of these parameters on system availability is analysed and given in tabular form. The findings of the paper are discussed with the plant personnel and are helpful to them for their future maintenance planning and for giving suggestions to the system designer for making suitable changes in design to reduce the failure in each unit. The need and the relevance for carrying out such a study have been described in the script. The actual failure and repair data on the identified condensate system has been used in the analysis.

\section{Structure of the paper}

The remainder of the paper is structured as follows:

The section 2 discusses the condensate system of thermal plant, system configuration, assumptions and notations for drawing the transition diagram. Section 3 describes the development of simulation model and its analysis, with brief introduction of Markov approach. Section 4 describes the performance evaluation of the system under study. Section 5 and 6 describes the results and concluding remarks respectively of developed simulation model.

\section{System Description}

\section{Condensate system}

Operating power plants efficiency is very important in the economics of power generation. This requires that all the systems function at their peak performance over long term operation. Condensate system helps the power plants to function efficiently and keeps them in continuous operation for optimal performance.

A thermal plant is a combination of systems and equipment in which the chemical energy of fossil fuels is converted into thermal energy which is then transferred to a working fluid (water) so as to convert it into steam at high pressure and temperature. This high pressure and temperature steam is then used for the development of power in a steam engine or turbine. According to Sharma (2006), in the boiler, the water 
is converted into steam with the help of heat produced by burning of coal. After doing the useful work in the steam turbine, the exhaust steam flows into a condenser where it is condensed to water. From the condenser, the condensed steam (condensate) is pumped to gland steam condenser through condensate extraction pump (CEP). After passing through gland steam condenser, it is passed through drain cooler and finally to deaerator, after its temperature is raised in low pressure heaters.

\section{System configuration}

The performance of the system depends on its configuration and performance of its subsystems. A typical system consists of a number of components or subsystems connected to each other logically either in series or in parallel in most cases. For the simulation modeling, the condensate system comprises of following six subsystems in series:

(i) Subsystem A consists of condenser. It is single unit arranged in series. Failure of this unit causes the complete failure of the system.

(ii) Subsystem B consists of gland steam condenser arranged in series. Failure of this unit causes the complete failure of the system.

(iii) Subsystem C consists of one drain cooler arranged in series. Failure of this unit causes the complete failure of the system.

(iv) Subsystem D consists of 03 low pressure heaters arranged in series. Failure of any one unit causes the complete failure of the system.

(v) Subsystem E consists of deaerator arranged in series. Failure of this unit causes the complete failure of the system.

(vi) Subsystem F consists of two condensate extraction pumps arranged in parallel; one operative and other in cold standby. Complete failure of the system will occur when both failed at a time.

\section{Assumptions}

The assumptions used in developing the probabilistic model are:

1. The states of all components are mutually independent (statistically independent).
2. There are repair and/or replacement facilities applied to the system and system failure/repair follows the exponential distribution.

3. Components do not fail simultaneously and the probability that two or more failed components could be repaired and switched to operation at the same time is zero.

4. When one component fails, it is instantaneously replaced by one of the standby subsystems if there is one.

5. A repaired system is as good as new, performance wise, for a specified duration and standby subsystems if any are of the same nature and capacity as that of active systems. (Gupta et al. (2008))

6. Failure/repair rates are constant over time and statistically independent. (Kumar et al. (2007)).

7. At any given time, the system is either in operating state or in the failed state. (Gupta et al. (2008 A)).

\section{Notations}

: Indicates the system is in full working state.

: Indicates the system is in failed state.

A,B,C,D,E,F : Represent full working states of subsystems.

$\mathrm{F}_{1} \quad$ : Denote that the subsystem $\mathrm{F}$ is working on standby unit.

a,b,c,d,e,f $\quad$ : Represent failed states of subsystems.

$\mathrm{P}_{0}(\mathrm{t}) \quad$ : Probability of the system working with full capacity at time't'

$\mathrm{P}_{1}(\mathrm{t}) \quad$ : Probability of the system in cold standby state.

$\mathrm{P}_{2}(\mathrm{t})$ to $\mathrm{P}_{12}(\mathrm{t})$ : Probability of the system in failed state.

$\phi_{\mathrm{i}} \mathrm{i}=1-6 \quad$ : $\quad$ Mean failure rates of A,B,C,D,E,F su systems respectively.

$\lambda_{\mathrm{i}}, \mathrm{i}=1-6 \quad$ : Mean repair rates of $\mathrm{A}, \mathrm{B}, \mathrm{C}, \mathrm{D}, \mathrm{E}, \mathrm{F}$ subsystems respectively.

$\mathrm{d} / \mathrm{dt} \quad$ : Represents the derivative w.r.t. time (t).

Av. $\quad$ : Steady state availability of the system. 


\section{System Simulation Modeling}

The simulation model for condensate system has been developed for making the stochastic analysis and performance evaluation using Markov concept.

\section{System state transition diagram}

Markov state transition diagram is helpful in analyzing reliability and availability of a repairable system. The transition probabilities only depend on the present state of the system. The flow of states for the present system under consideration has been described in a transition diagram, as shown in figure 1 , which is logical representation of all possible state's probabilities encountered during the failure analysis of condensate system (Kumar et al. (1999)). The failure and repair rates of the different subsystems are used as standard input information to the model. Formulation is carried out using the joint probability functions based on the transition diagram.

$$
P_{0}(t+\Delta t)=(1-\lambda t) \cdot P_{0}(t)
$$

Similarly $P_{1}(t+\Delta t)=(\phi \cdot \Delta t) \cdot P_{0}(t)+(1-\lambda \cdot \Delta t) \cdot P_{1}(t)(2)$

The Eq. 2 shows the probability of one occurrence in time ( $\mathrm{t}$ $+\Delta \mathrm{t}$ )and is composed of two parts, namely, (a) probability of zero occurrences in time t multiplied by the probability of one occurrence in the interval $\Delta \mathrm{t}$ and (b) the probability of one occurrence in time t multiplied by the probability of no occurrences in the interval $\Delta \mathrm{t}$, as stated by Srinath (1994). Then simplifying and putting $\Delta t \rightarrow 0$, one gets

$$
\left(\frac{d}{d t}+\phi\right) P_{1}(t)=\lambda \cdot P_{0}(t)
$$

\section{Mathematical formulation for simulation model}

The steady state availability definition lends itself well to experimental evaluation and may be determined in terms of

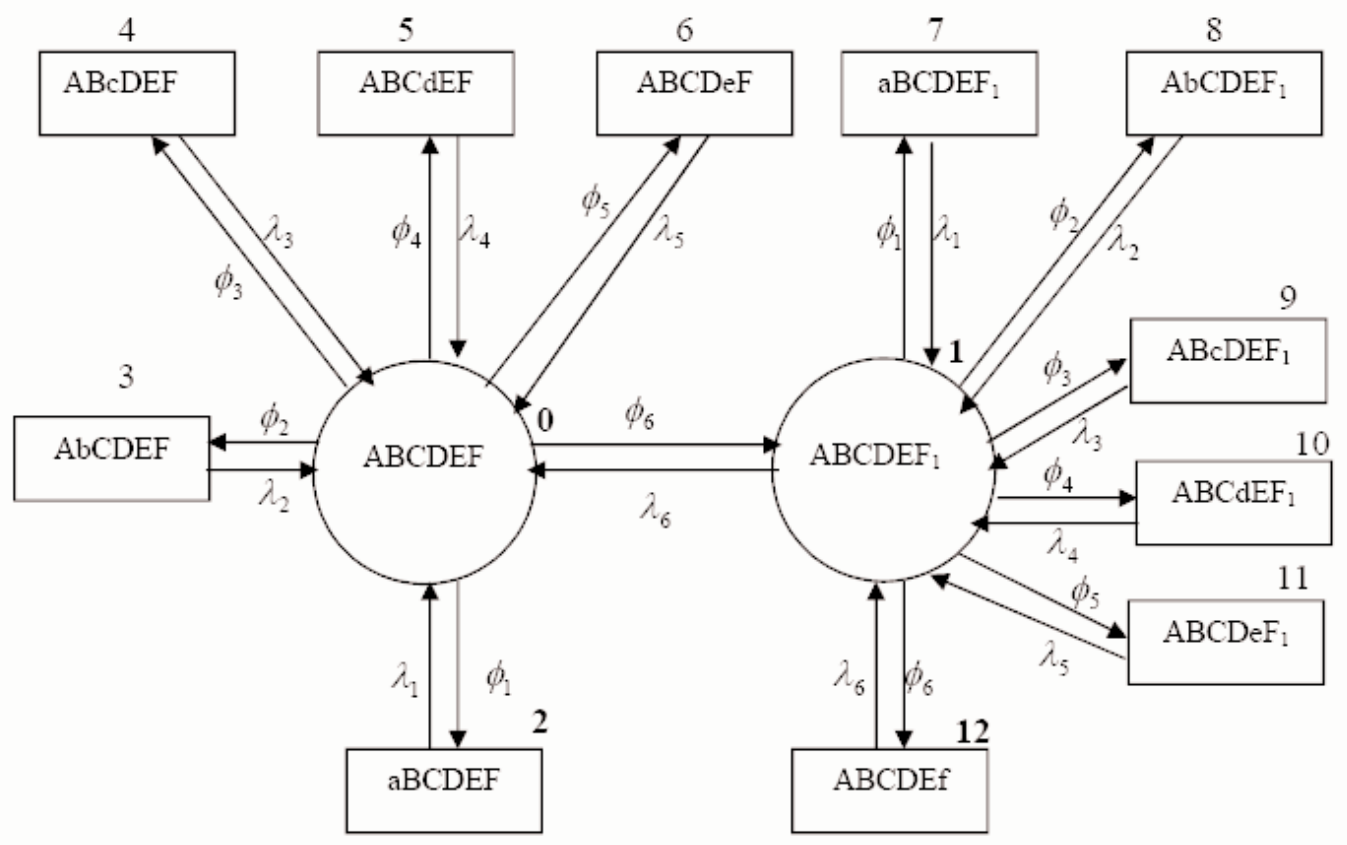

Fig.1: Transition diagram of condensate system

\section{Markov approach}

According to Markov if $P_{0}(t)$ represent the probability of zero occurrences in time t. The probability of zero occurrences in time $(\mathrm{t}+\Delta \mathrm{t})$ is given by Equation (Eq.). 1; i.e. measured system mean time to failure (MTTF) and system mean time to repair (MTTR) as

$$
A_{s s}=\frac{M T T F}{M T T F+M T T R}=\frac{M T T F}{M T B F}
$$

Eq. (1) is always valid if it is assumed that after each repair 
the system is restored to its original state. Under these circumstances, the limiting availability does not depend on the nature of the lifetime and repair distributions.

Using the concept used in Eq. 3 and various probability considerations, the following differential Equations associated with the transition diagram of condensate system are formed, as described by Kumar et al. (2007).

$$
\begin{aligned}
& \left(d / d t+\sum_{i=1}^{6} \phi_{i}\right) P_{0}(t)=\sum_{i=1}^{5} \lambda_{i} P_{1+i}(t)+\lambda_{6} P_{1}(t) \\
& \left(d / d t+\sum_{i=1}^{6} \phi_{i}+\lambda_{6}\right) P_{1}(t)=\sum_{i=1}^{6} \lambda_{i} P_{6+i}(t)+\phi_{6} P_{0}(t) \\
& \left(d / d t+\lambda_{m}\right) P_{i}(t)=\phi_{m} P_{j}(t)
\end{aligned}
$$

Where as for Eq. 7

$$
\text { For } \begin{array}{r}
m=1 \quad i=2,7 \quad \text { and } j=0,1 \text { respectively; } \\
m=2 \quad i=3,8 \text { and } j=0,1 \text { respectively; } \\
m=3 \quad i=4,9 \text { and } j=0,1 \text { respectively; } \\
m=4 \quad i=5,10 \text { and } j=0,1 \text { respectively; } \\
m=5 \quad i=6,11 \text { and } j=0,1 \text { respectively; } \\
m=6 \quad i=12 \quad \text { and } j=1 \text { respectively; }
\end{array}
$$

With the initial condition $\mathrm{P}_{0}(0)=1$ and zero otherwise.

\section{Analysis of simulation model}

Since any thermal plant is a process industry where raw material is processed through various subsystems continuously till the final product is obtained. Then according to Arora et al. (1997), to get the long run availability of the system i.e steady state, put derivative of all probability equal to zero, in to differential Eq. (5-7)

$$
\text { i.e } \quad \frac{d}{d t} P_{i}(t)=0 \text { at } \quad t \rightarrow \infty
$$

And solving these equations recursively, following are the values of all probabilities in terms of full working state probability i.e. $\mathrm{P}_{0}$.

$$
\begin{array}{ll}
P_{1}=\left(\phi_{6} / \lambda_{6}\right) P_{0} & P_{7}=\left(\phi_{1} / \lambda_{1}\right)\left(\phi_{6} / \lambda_{6}\right) P_{0} \\
P_{2}=\left(\phi_{1} / \lambda_{1}\right) P_{0} & P_{8}=\left(\phi_{2} / \lambda_{2}\right)\left(\phi_{6} / \lambda_{6}\right) P_{0} \\
P_{3}=\left(\phi_{2} / \lambda_{2}\right) P_{0} & P_{9}=\left(\phi_{3} / \lambda_{3}\right)\left(\phi_{6} / \lambda_{6}\right) P_{0} \\
P_{4}=\left(\phi_{3} / \lambda_{3}\right) P_{0} & P_{10}=\left(\phi_{4} / \lambda_{4}\right)\left(\phi_{6} / \lambda_{6}\right) P_{0} \\
P_{5}=\left(\phi_{4} / \lambda_{4}\right) P_{0} & P_{11}=\left(\phi_{5} / \lambda_{5}\right)\left(\phi_{6} / \lambda_{6}\right) P_{0} \\
P_{6}=\left(\phi_{5} / \lambda_{5}\right) P_{0} & P_{12}=\left(\phi_{6} / \lambda_{6}\right)\left(\phi_{6} / \lambda_{6}\right) P_{0}
\end{array}
$$

\section{Steady state availability}

The probability of full working capacity, namely, $\mathrm{P}_{0}$ determined by using normalizing condition: (i.e sum of the probabilities of all working states and failed states is equal to 1)

i.e $\quad \sum_{i=0}^{12} P_{i}=1$

Therefore putting the values of $\mathrm{P}_{0}-\mathrm{P}_{12}$ and solving, one gets

$P_{0}=1 /\left(\left(1+\left(\phi_{1} / \lambda_{1}\right)+\left(\phi_{2} / \lambda_{2}\right)+\left(\phi_{3} / \lambda_{3}\right)+\left(\phi_{4} / \lambda_{4}\right)\right.\right.$

$\left.+\left(\phi_{5} / \lambda_{5}\right)+\left(\phi_{6} / \lambda_{6}\right) *\left(1+\phi_{6} / \lambda_{6}\right)\right)$

The steady state availability of condensate system may be obtained as summation of all working state's probabilities as:

$$
\begin{aligned}
& A v .=\sum_{i=0}^{1} P_{i}=P_{0}+P_{1} \\
& =P_{0}+\frac{\phi_{6}}{\lambda_{6}} P_{0} \\
& A v .=P_{0}\left(1+\frac{\phi_{6}}{\lambda_{6}}\right)
\end{aligned}
$$

\section{Performance Evaluation}

The performance of condensate system of thermal power plant is mainly affected by the failure and repair rates of each subsystem. The developed model includes all possible states of nature, that is, failure events $\left(\phi_{i}\right)$ and the identification of all the courses of action, i.e, repair priorities $\left(\lambda_{i}\right)$. From maintenance history sheet of condensate system and through 
the discussions with the plant personnel, appropriate failure and repair rates of all subsystems are taken and performance matrices (availability values) are prepared accordingly by putting these failure and repair rates values in expression 9, which is the system availability simulation model $\left(A_{V}\right.$.). Performance evaluation forms the foundation for all other performance improvement activities (e.g. solution design and development, implementation and analysis). The simulation model is used to predict the availability/performance of condensate system for known input values of failure and repair rates of its subsystems. Tables I-VI represent the availability matrices for various subsystems of the condensate system. These matrices simply reveal the various availability levels for different combinations of failure and repair rates/priorities, which further helps in maintenance decisions. These availability matrices are then plotted and shown in Figure 2-7. On the basis of analysis made, the best possible combinations $(\phi, \lambda)$ may be selected.

\section{Results and Discussion}

The performance of each subsystem is analyzed using the developed model. On the basis of availability values as given in Tables I-VI, the following observations are made, which reveals the effect of failure and repair rates of various subsystems on the availability of condensate system.

\section{Subsystem A: Condenser}

Table I and Figure 2 reveal the effect of failure and repair rates of condenser subsystem on the availability of condensate system. It is observed that for some known values of failure / repair rates of gland steam condenser, drain cooler, low pressure heaters, deaerator and condensate extraction pump, as failure rate of condenser increases from 0.005 (once in $200 \mathrm{hrs}$ ) to 0.01 (once in $100 \mathrm{hrs),} \mathrm{the} \mathrm{unit} \mathrm{availabil-}$ ity decreases by only $3 \%$. Similarly as repair rate of condenser increases from 0.1 (once in $10 \mathrm{hrs)} \mathrm{to} 0.5$ (once in 2 hrs), the unit availability increases by about $3 \%$.

\section{Subsystem B: Gland steam condenser}

Table II and Figure 3 reveal the effect of failure and repair rates of gland steam condenser subsystem on the availability of condensate system. It is observed that for some known values of failure / repair rates of condenser, drain cooler, low pressure heaters, deaerator and condensate extraction pump, as failure rate of gland steam condenser increases from 0.0067 (67 failures in $10000 \mathrm{hrs)}$ to 0.0135 (135 failures in $10000 \mathrm{hrs}$ ), the unit availability decreases by only $4 \%$. Similarly as repair rate of gland steam condenser increases from 0.1 (once in $10 \mathrm{hrs}$ ) to 0.2 (once in $5 \mathrm{hrs}$ ), the unit availability increases by about $2 \%$.

\section{Subsystem C: Drain cooler}

Table III and Figure 4 reveal the effect of failure and repair rates of drain cooler subsystem on the availability of condensate system. It is observed that for some known values of failure / repair rates of condenser, gland steam condenser, low pressure heaters, deaerator and condensate extraction pump, as failure rate of drain cooler increases from 0.033 (33 failures in $1000 \mathrm{hrs}$ ) to 0.005 (once in $200 \mathrm{hrs}$ ), the unit availability decreases by only .5\%. Similarly as repair rate of drain cooler increases from 0.2 (once in 5 hrs) to 0.5 (once in $2 \mathrm{hrs}$ ), the unit availability increases by about $1 \%$.

\section{Subsystem D: Low pressure heaters}

Table IV and Figure 5 reveal the effect of failure and repair rates of low pressure heaters subsystem on the availability of condensate system. It is observed that for some known values of failure / repair rates of condenser, gland steam condenser, drain cooler, deaerator and condensate extraction pump, as failure rate of low pressure heaters increases from 0.005 ( 5 failures in $1000 \mathrm{hrs}$ ) to 0.01 (once in $100 \mathrm{hrs),} \mathrm{the}$ unit availability decreases by only $3 \%$. Similarly as repair rate of low pressure heaters increases from 0.1 (once in 10 hrs) to 0.4 (once in $2.5 \mathrm{hrs}$ ), the unit availability increases by about $2 \%$.

\section{Table I. Performance matrix of condenser subsystem of condensate system}

\begin{tabular}{|c|c|c|c|c|c|c|}
\hline \multicolumn{7}{|c|}{$\rightarrow$ Availability (Av) $\rightarrow \mathrm{A}_{0}$} \\
\hline$\phi_{1}^{\lambda_{1}}$ & .1 & .2 & .3 & .4 & .5 & $\begin{array}{l}\text { Constant } \\
\text { values }\end{array}$ \\
\hline $\begin{array}{l}.005 \\
.0063 \\
.0076 \\
.0089 \\
.0102\end{array}$ & $\begin{array}{l}.7774 \\
.7697 \\
.7620 \\
.7546 \\
.7483\end{array}$ & $\begin{array}{l}.7929 \\
.7888 \\
.7848 \\
.7808 \\
.7768\end{array}$ & $\begin{array}{l}.7981 \\
.7954 \\
.7926 \\
.7899 \\
.7872\end{array}$ & $\begin{array}{l}.8008 \\
.7987 \\
.7966 \\
.7946 \\
.7925\end{array}$ & $\begin{array}{l}.8024 \\
.8007 \\
.7991 \\
.7974 \\
.7958\end{array}$ & $\begin{array}{l}\phi_{2}=.0101, \lambda_{2}=.15 \\
\phi_{3}=.0041, \lambda_{3}=.35 \\
\phi_{4}=.0076, \lambda_{4}=.25 \\
\phi_{5}=.0033, \lambda_{5}=.187 \\
\phi_{6}=.03, \quad \lambda_{6}=.275\end{array}$ \\
\hline
\end{tabular}




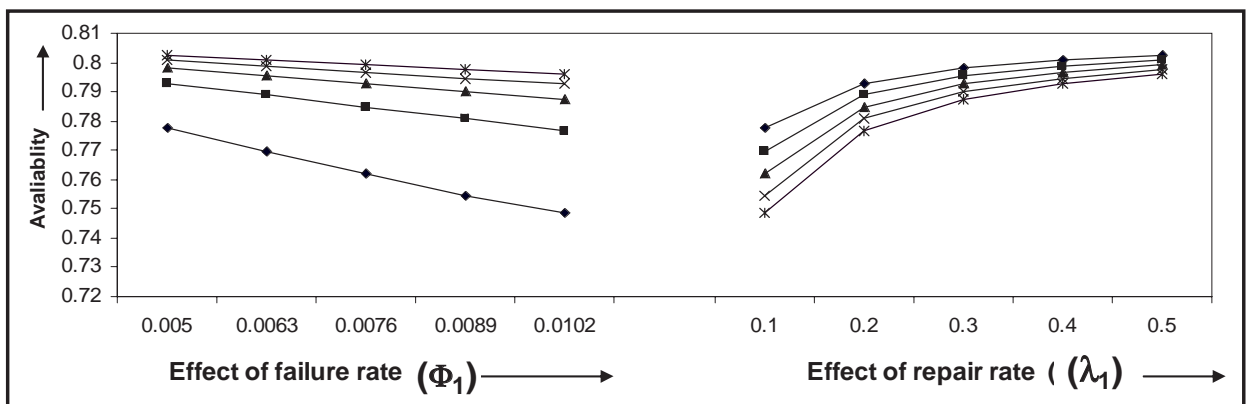

Fig. 2. Effect of failure \& repair rate of condenser subsystem on system availability.

Table II. Performance matrix of gland steam condenser subsystem of condensate system $\rightarrow$ Availability (Av) $\rightarrow \mathrm{A}_{0}$

\begin{tabular}{l|l|l|l|l|l|l}
\hline \multicolumn{1}{c|}{$\lambda_{2}$} & .1 & .125 & .150 & .175 & .2 & Constant values \\
\hline$\phi_{2}$ & & & & & & \\
\hline .0067 & .7929 & .8014 & .8071 & .8113 & .8145 & $\phi_{1}=.0076, \lambda_{1}=.3$ \\
.0084 & .7823 & .7927 & .7998 & .8050 & .8089 & $\phi_{3}=.0041, \lambda_{3}=.35$ \\
.0101 & .7720 & .7843 & .7926 & .7987 & .8034 & $\phi_{4}=.0076, \lambda_{4}=.25$ \\
.0118 & .7620 & .7760 & .7856 & .7926 & .7979 & $\phi_{5}=.0033, \lambda_{5}=.187$ \\
.0135 & .7523 & .7679 & .7787 & .7865 & .7925 & $\phi_{6}=.03, \lambda_{6}=.275$ \\
\hline
\end{tabular}

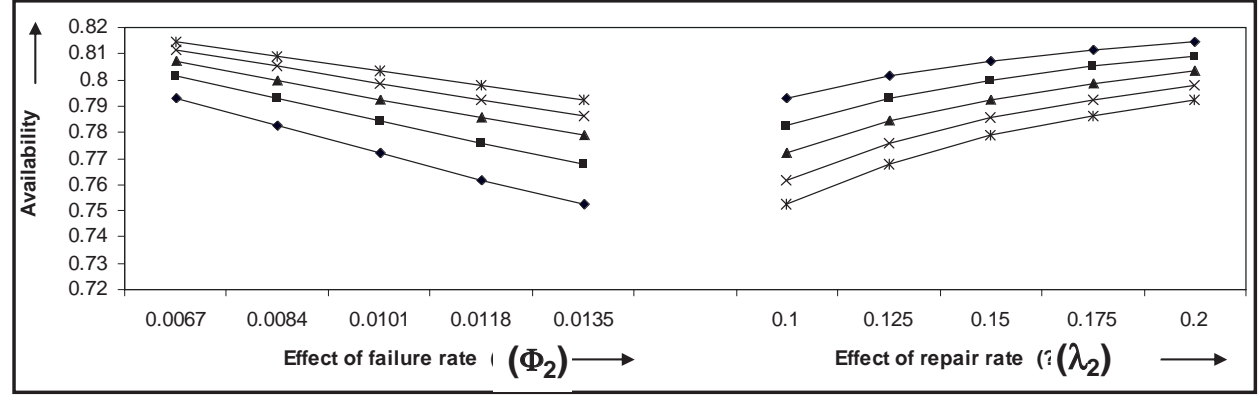

Fig 3. Effect of failure \& repair rate of gland steam condenser on system availability.

Table III. Performance matrix of drain cooler subsystem of condensate system

$\rightarrow$ Availability $(\mathrm{Av}) \rightarrow \mathrm{A}_{0}$

\begin{tabular}{l|l|l|l|l|l|l}
\hline \multicolumn{1}{c|}{$\lambda_{3}$} & .2 & .275 & .350 & .425 & .5 & Constant values \\
\hline$\phi_{3}$ & & & & & & \\
\hline .0033 & .7896 & .7925 & .7941 & .7951 & .7959 & $\phi_{1}=.0076, \lambda_{1}=.3$ \\
.0037 & .7884 & .7916 & .7934 & .7945 & .7954 & $\phi_{2}=.0101, \lambda_{2}=.15$ \\
.0041 & .7872 & .7906 & .7926 & .7939 & .7949 & $\phi_{4}=.0076, \lambda_{4}=.25$ \\
.0045 & .7859 & .7897 & .7919 & .7934 & .7944 & $\phi_{5}=.0033, \lambda_{5}=.187$ \\
.0049 & .7847 & .7887 & .7911 & .7929 & .7939 & $\phi_{6}=.03, \lambda_{6}=.275$ \\
\hline
\end{tabular}




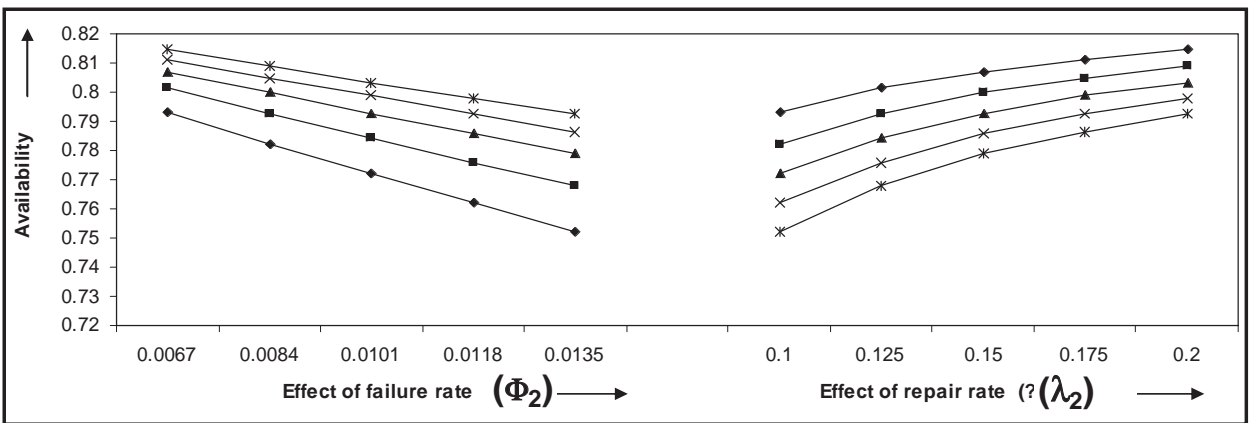

Fig. 4. Effect of failure \& repair rate of drain cooler subsystem on system availability.

Table IV. Performance matrix of low pressure heaters subsystem of condensate system

$$
\rightarrow \text { Availability (Av) } \rightarrow \mathrm{A}_{0}
$$

\begin{tabular}{l|l|l|l|l|l|l}
\multicolumn{1}{c|}{$\lambda$} & .1 & .175 & .250 & .305 & .4 & $\begin{array}{l}\text { Constant } \\
\text { values }\end{array}$ \\
\hline$\phi_{4}$ & & & & & & \\
\hline .005 & .7805 & .7938 & .7992 & .8015 & .8041 & $\phi_{1}=.0076, \lambda_{1}=.3$ \\
.0063 & .7727 & .7891 & .7959 & .7988 & .8020 & $\phi_{2}=.0101, \lambda_{2}=.15$ \\
.0076 & .7650 & .7845 & .7926 & .7961 & .7999 & $\phi_{3}=.0041, \lambda_{3}=.35$ \\
.0089 & .7575 & .7800 & .7893 & .7934 & .7978 & $\phi_{5}=.0033, \lambda_{5}=.187$ \\
.0102 & .7501 & .7755 & .7862 & .7907 & .7957 & $\phi_{6}=.03, \lambda_{6}=.275$ \\
\hline
\end{tabular}

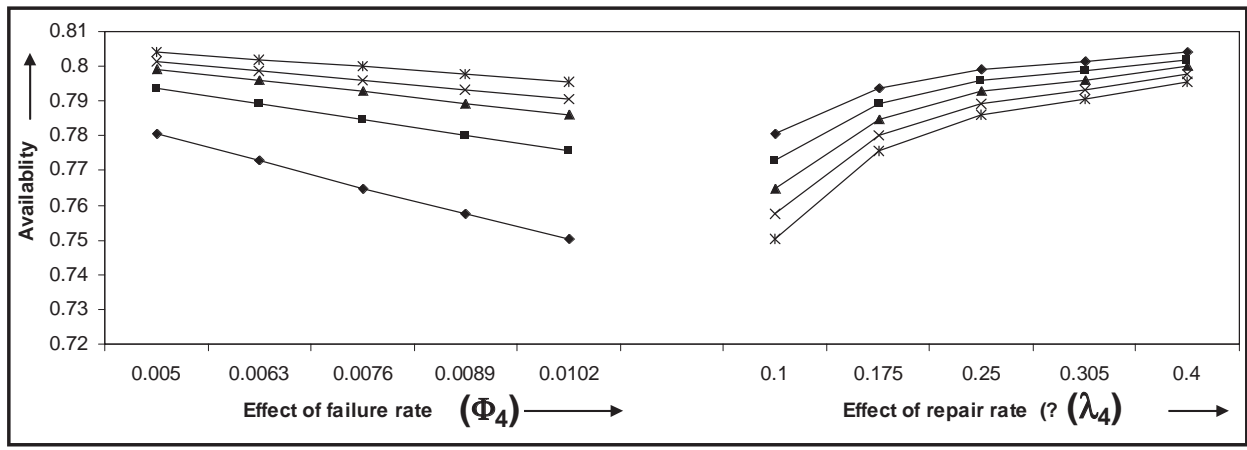

Fig. 5. Effect of failure \& repair rate of low pressure heaters subsystem on system availability.

\section{Subsystem E: Deaerator}

Table $\mathrm{V}$ and Figure 6 reveal the effect of failure and repair rates of deaerator subsystem on the availability of condensate system. It is observed that for some known values of failure / repair rates of condenser, gland steam condenser, drain cooler, low pressure heaters, and condensate extraction pump, as failure rate of deaerator increases from 0.0025 (25 failures in $10000 \mathrm{hrs)}$ to 0.0041 (41 failures in $10000 \mathrm{hrs),}$ the unit availability decreases by only $1 \%$. Similarly as repair rate of deaerator increases from 0.125 (once in $8 \mathrm{hrs}$ ) to 0.25 (once in 4 hrs), the unit availability increases by about .5\%. 
Table V. Performance matrix of deaerator subsystem of condensate system

\begin{tabular}{c||l|l|l|l|l||l}
\multicolumn{9}{c}{$\rightarrow$ Availability (Av) $\rightarrow \mathrm{A}_{0}$} \\
\hline$\lambda_{5}$ & .125 & .156 & .187 & .218 & .25 & $\begin{array}{l}\text { Constant } \\
\text { values }\end{array}$ \\
\hline .0025 & .7912 & .7937 & .7953 & .7965 & .7975 & $\phi_{1}=.0076, \lambda_{1}=.3$ \\
.0029 & .7892 & .7921 & .7940 & .7954 & .7965 & $\phi_{2}=.0101, \lambda_{2}=.15$ \\
.0033 & .7872 & .7904 & .7926 & .7942 & .7954 & $\phi_{3}=.0041, \lambda_{3}=.35$ \\
.0037 & .7852 & .7888 & .7913 & .7931 & .7944 & $\phi_{4}=.0076, \lambda_{4}=.25$ \\
.0041 & .7832 & .7873 & .7900 & .7919 & .7934 & $\phi_{6}=.03, \lambda_{6}=.275$ \\
\hline
\end{tabular}

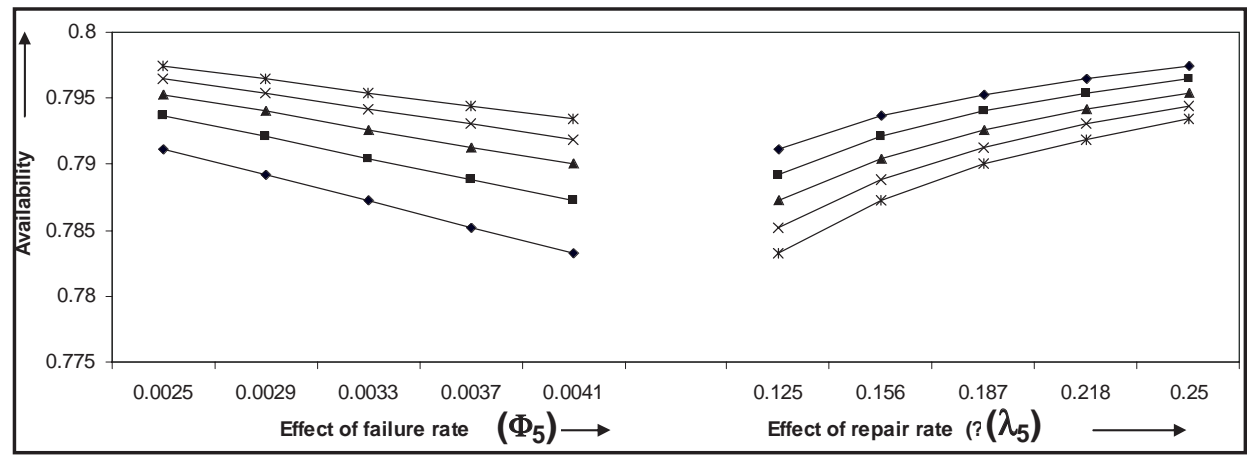

Fig. 6. Effect of failure \& repair rate of deaerator subsystem on system availability.

\section{Subsystem F: Condensate extraction pumps}

Table VI and Figure 7 reveal the effect of failure and repair rates of condensate extraction pump subsystem on the availability of condensate system. It is observed that for some known values of failure / repair rates of condenser, gland steam condenser, drain cooler, low pressure heaters and deaerator, as failure rate of condensate extraction pump increases from 0.01 (once in $100 \mathrm{hrs}$ ) to 0.05 (once in 20hrs), the unit availability decreases by only $17 \%$. Similarly as repair rate of condensate extraction pump increases from 0.125 (once in $8 \mathrm{hrs}$ ) to 0.425 (once in $2.3 \mathrm{hrs}$ ), the unit availability increases by about $4 \%$.

Table VI. Performance matrix of condensate extraction pump subsystem of condensate system

$\rightarrow$ Availability $(\mathrm{Av}) \rightarrow \mathrm{A}_{0}$

\begin{tabular}{l|l|l|l|l|l|l}
\hline \multicolumn{1}{r|}{$\lambda_{6}$} & .125 & .2 & .275 & .350 & .425 & $\begin{array}{l}\text { Constant } \\
\text { values }\end{array}$ \\
\hline .01 & & & & & & \\
.02 & .8114 & .8316 & .8411 & .8467 & .8503 & $\phi_{1}=.0076, \lambda_{1}=.3$ \\
.03 & .7619 & .7984 & .8162 & .8267 & .8336 & $\phi_{2}=.0101, \lambda_{2}=.15$ \\
.04 & .7181 & .7677 & .7926 & .8076 & .8176 & $\phi_{3}=.0041, \lambda_{3}=.35$ \\
.05 & .6791 & .7394 & .7704 & .7894 & .8022 & $\phi_{4}=.0076, \lambda_{4}=.25$ \\
& .6441 & .7130 & .7494 & .7720 & .7721 & $\phi_{5}=.0033, \lambda_{5}=.187$ \\
\hline
\end{tabular}






Fig. 7. Effect of failure \& repair rate of condensate extraction pump on system availability.

\section{Conclusion}

The model is effectively used for evaluation of performance of various sub-systems of condensate system, which further helps in maintenance decisions. The system availability has been excellent, mainly because of the low failure rates, supported by the state of the art repair facilities. It can be concluded from Figures 2-7 and Tables I-VI, that as failure rate increases, the availability goes on decreasing and as repair rate increases, the availability goes on increasing. The expression 9 depicts the availability simulation model, which further helps in analysis and evaluating the performance of various subsystems of condensate system of thermal plant. Performance matrices as given in Table I-VI and Figures 2-7, clearly shows that condensate extraction pump (CEP) subsystem is most critical subsystem as far as maintenance is concerned and required immediate attention, as the effect of its failure rates on the system availability is much higher (17\%) than other five subsystems. Further, drain cooler subsystem is least critical, as the effect of its failure rates on the system availability is very less (.5\% only). Such results are found highly beneficial to the plant management for the availability analysis of condensate system of a thermal plant.

\section{Acknowledgement}

The author is grateful to Sh. Sushil Bansal Ji, SE, Panipat Thermal Power Plant (No.5), Panipat, for providing every possible helow pressure during the work.

\section{References}

Arora N. and Kumar, D. (1997) Availability analysis of steam and power generation system in thermal power plant, Micro electron Reliability 37(5): 95-99.

Arora N. and Kumar D. (1993) Maintenance planning and management of coal crushing system in the thermal power plant. Proc. of ORSI 26th Cony. Bhubaneshwar, India.

Arora N., Kumar D. and Yadav V. (1995) Reliability analysis and maintenance planning of coal conveyor system in a thermal power plant. Proc. of AIEPIT, D13-18. Allahabad, India.

Balaguruswamy E. (1984) Reliability Engineering, New Delhi, Tata McGraw Hill.

Boudali H. and Dugan J. B. (2005) A discrete-time Bayesian network reliability modeling and analysis framework. Reliability Engineering and System Safety 87: 337349.

Butler R. (1986) The SURE Reliability Analysis Program. AIAA Guidance, Navigation, and Control Conference.

Ciardo G., Muppala J. and Trivedi K. (1989) Stochastic petri net package; In: Proc. 3rd Int. Workshop on Petri Nets and performance model: 142-151.

Corder A. S. (1976) Maintenance Management Technique. U.K., McGraw-Hill.

Dhillon, B. S. (1983) Reliability Engineering in Systems Design and Operation, New York Van NostrandReinhold.

Fishman G. S. (1986) A Monte Carlo sampling plan for esti- 
mating network reliability, Opns Res., 34: 581-594.

Goel L. R. and Shrivastava, P. (1991) Profit analysis of a two-unit redundant system with provision for rest and correlated failures and repairs. Microelectron. Reliab., 31: 827-833.

Goel L. R., Tyagi P. K. and Gupta R. (1994) Analysis of a standby system with dependent repair time and slow switching device. Microelectron. Reliab., 34: 383-386.

Goel L. R., Tyagi P. K. and Gupta R. (1995) Analysis of a two-unit standby system with preparation time and correlated failure and repairs. Microelectron. Reliab., 35: 1163-1165.

Gupta S., Tewari P. C. and Sharma A. K. (2008) Reliability and availability analysis of ash handling unit of a steam thermal power plant. International Journal of Engineering Research and Industrial Applications, 1(V): 53-62.

Gupta S., Tewari P. C. and Sharma A. K. (2008A) Performance modeling and decision support system of feed water unit of a thermal power plant, South African Journal of Industrial Engineering. (Accepted for publication in Nov. 2008).

James Stanley and Gary Malhoit, 2001 Spread sheet Markov analysis for plant power reliability. Journal of Quality Engineering 13(3): 457-464.

Kiureghian A. D. and_Ditlevsen O. D. and Song, J. (2007) Availability, reliability and downtime of systems with repairable components. Reliability Engineering and System Safety 92: 231-242.

Koren J. M. and Gaertner J. (1987) CAFTA: A Fault tree analysis tool designed for PSA; In: Proc. of Probabilistic Safety Assessment and Risk Management 2: 588-592.

Krishnamurthi G., Gupta A. and Somani A. K. (1996) The HIMAP modeling environment, In: Proceedings of the 9th International Conference on Parallel and Distributed Computing Systems: 254-259.
Kumamoto H., Tanaka K. and Inoue K. (1977) Efficient evaluation of system reliability by Monte Carlo method, IEEE Trans. Reliab., R-26: 311-315.

Kumar S., Tewari P. C. and Sharma R. (2007) Simulated availability of $\mathrm{CO}_{2}$ cooling system in a fertilizer plant, Industrial Engineering Journal (Indian Institution of Industrial Engineering, Mumbai) 36(10): 19-23.

Kumar S., Kumar D. and Mehta N. P. (1999) Maintenance management for ammonia synthesis system in a urea fertilizer plant, International Journal of Management and System 15(3): 211-214.

Kumar S., Tewari P. C. and Kumar S. (2007) Performance modeling and simulated availability of shell gasification and carbon recovery system of urea plant. Proceedingland steam of the 16th IASTED International Conference, 409-413.

Lieberman N. P., (1973) Process Design for Reliable Operation. Huston, TX: Gulf Publishing Company.

Mazumdar, M. (1975) Importance sampling in reliability estimation, In Reliability and fault tree analysis, R. Barlow, J. Fussel, N. Singpurwalla (eds), 153-165: SIAM, Philadelow pressurehia.

Ocon R. P. and Cazorla D. M. (2004) A multiple system governed by a quasi-birth-and-death process. Reliability Engineering and System Safety 84: 187-196.

Osaki S. (1980) A two-unit parallel redundant system with bivariate exponential life times. Microelectron. Reliab., 20: 521-523.

Pijnenburg M., Ravichandran N. and Regterschof G. (1993) Stochastic analysis of a dependent parallel system. European J. Op Res., 68: 90-104.

Rajamanickam P. and Chandrasekar, B. (1997) Reliability measures for two-unit systems with a dependent structure for failure and repair times, Microelectron. Reliab., 37(5): 829-833.

Raje D. V., Olaniya R. S., Wakhare P. D. and Deshpande A.W. (2000) Availability assessment of a two-unit stand-by pumping system. Reliability Engineering and 
System Safety, 68: 269-274.

Ravichandran, N. (1981) Analysis of a two-unit parallel system with phase type failure general repairs. Microelectron.Reliab., 21(4): 567-572.

Sahner R. A. Trivedi K. S. and Puliafito A., (1996) Performance and reliability analysis of computer systems, Boston, MA, Kluwer Academic.
Sharma P .C. (2006) Power Plant Engineering, N. Delhi, S.K.Kataria and sons.

Somani A. K., Ritcey J. A. and Au S. H. (1992) computationally efficient phased mission reliability analysis for systems with variable configuration. IEEE Transactions on Reliability, 41(4): 504-511.

Srinath L. S. (1994) Reliability Engineering, 3rd edition, New Delhi, India, East-West Press Pvt. Ltd.

Received : November 30, 2008;

Accepted : April 16, 2009 